Sharif University of Technology
Scientia Iranica
Transactions E: Industrial Engineering
hCIENTIA

Research Note

\title{
Efficiency assessment of Iranian handmade carpet company by network DEA
}

\author{
S.H. Zegordi* and A. Omid \\ Faculty of Industrial \& Systems Engineering, Tarbiat Modares University, Tehran, Iran.
}

Received 11 April 2014; received in revised form 5 November 2015; accepted 12 November 2016

\section{KEYWORDS}

Data envelopment

analysis;

Efficiency;

Multistage;

Multi-objective;

Network;

Undesired outputs.

\begin{abstract}
Different categories of Iranian handmade carpet are produced each year. Due to resource limitation, it is so important for managers to allocate more resources to the most efficient categories. Therefore, the main purpose of this illustration is to consider most efficient types of carpet in production and sales stages. To do so, different categories of Iranian handmade carpet are considered as DMUs. This study utilizes network DEA for constructing a model to analyze total and partial efficiencies of Iranian Handmade Carpet Company (IHCC), simultaneously. IHCC consists of three main departments that are working jointly to maximize productivity of the firm; therefore, the case of IHCC is a multi-stage system with shared intermediate variables, extra inputs to the second stage, and undesired outputs. The novelty of this paper is the methodology used for calculating the efficiency, which is based on multi-objective programming. Results of experimental data of IHCC are summarized in order to prepare some brilliant management strategies based on partial and total efficiency scores of different carpet categories. Because of the lack of familiar researches in the area of carpet industry efficiency measurement, this research will provide valuable information for decision makers.
\end{abstract}

(C) 2018 Sharif University of Technology. All rights reserved.

\section{Introduction}

Resource allocation is one of the most important issues for companies, especially for an enormous industry such as handmade carpet texture. It is important to note that resource limitations is an inseparable issue in each business, so how to allocate budget and resources among different activities is a crucial task for all managers; if managers allocate the greatest amount of resources to the most efficient activities, productivity and profit of the company will increase. Thus, due to

\footnotetext{
*. Corresponding author. Tel.: +982182883394; Fax: +982188005040

E-mail addresses: zegordi@modares.ac.ir (S.H. Zegordi); azade.omid@modares.ac.ir (A.Omid)
}

doi: $10.24200 /$ sci. 2017.20006 the shortage of resources, it is so essential to allocate resources to the most efficient products. Analysis of historical data can also help managers to do this duty successfully. According to the efficiency scores of different DMUs, experts can make suggestions about which DMU performs better and has priority for more investigation; additionally, if performance score of a DMU is poor, partial efficiency scores of sub-processes can help managers to realize which sub-process needs to be strengthened in order to maximize the overall performance.

In handmade carpet industry, there are different categories of carpets, which are distinguished by design, color, size, raw material, and the proficiency of weavers; Carpet specialists classify these different types of carpet in some particular categories, which are mostly named by the geographic region in which the carpets are woven. Production costs of these categories are 
different based on different weavers' wages depending on gender and geographic region; in addition, different kinds of raw materials with different prices are used such as wool, silk, fluff, lint, etc.

From a managerial point of view, performance of the carpet industry is the aggregated efforts of different departments, involving both the production and the sales departments. Sales department consists of two major markets: internal market and external market, which work jointly to maximize the productivity of the company. Besides, there is changeable demand for distinct kinds of carpet in the internal and external markets; some are sold better in the local markets and some are better to be exported. Hence, it is so important to perceive which category is more efficient in production and marketing.

Therefore, if we assume each category of handmade carpets as a DMU; it is so crucial for decision makers to know which DMU works efficiently, since it can help managers to allocate more budgets to the respective category for the next year. In addition, partial efficiency can benefit managers a lot. If managers get access to the partial efficiency scores of different departments, they can understand which component is inefficient. Thus, specialists will focus on this department and, by empowering it, and will enhance the overall efficiency of the DMU.

To the knowledge of the authors, there is no research done yet in the field of measuring the performance of handmade carpet texture industry. This study provides new methodology for measuring the efficiency of a network structure, which is based on multi-objective programming, to maximize total and partial efficiencies, simultaneously; therefore, for the first time, a method is applied to a handmade carpet company case.

For ease of notation, Section 2 begins with reviewing relevant literature; then, in Section 3, we introduce our approach to model multi-stage system of Iranian Handmade Carpet Company (IHCC). Section 4 provides illustrative example of IHCC; besides, results of efficiency scores, which are measured by means of the proposed network DEA methodology, are summarized. Then, in Section 5, discussions about the results are developed. Conclusions are given in the last section.

\section{Literature review}

Data Envelopment Analysis (DEA) was introduced in 1978 for measuring relative efficiency of peer Decision Making Units (DMUs) [1]. DEA has been widely recognized as an effective technique for measuring the relative efficiency of a set of DMUs that apply multiple inputs to produce multiple outputs, with many theoretical developments and practical applications being reported (for example, the review of Cook and
Seiford [2]; Emrouznejad et al. [3]; Liu et al. [4,5]; and Zhou et al. [6]).

Although DEA has been applied in many different fields, DMUs have traditionally been seen as black boxes with inputs and outputs, but without any consideration of what is happening inside the DMU [7]. Traditional DEA models failed to measure the efforts of different processes and sub-processes within the organization [8]. Another issue that should be noted is that ignoring the operations of the component processes may end in misleading results; a number of examples have been presented to show that an overall system may be efficient even if all component processes are not [9]. More significantly, there are cases in which all the component processes of a DMU perform worse than those in another DMU, yet they have better system performance [10]. To overcome this, many studies in the area of network structure efficiency measurement have been done; Kao published a literature review article about network data envelopment analysis that classified models used in network systems in an appropriate manner [11]; some develop models to measure efficiencies under specified conditions, some examine the properties possessed by certain models, and others apply existing models to solve real-world problems. Cook et al. reviewed a number of models for the basic two-stage system, which had only two processes connected in series, with the second only consuming all the outputs from the first stage [12]. Conversely, quite a few researches focused on general multi-stage network with extra inputs and outputs. As an instance, Tone and Tsutsui proposed a Slacks-Based Measure (SBM) model to measure the system and process efficiencies of a network system with extra inputs and outputs [13]. Kao transformed the nonlinear model into a linear one using a variable substitution technique [14]. In addition, for network structures with more than two stages, Kao proposed the relational network DEA model [15]. Hiseh and Lin utilized relational network data envelopment analysis to construct a model to analyze the efficiency and effectiveness of an international tourist hotel [16]. Liu and Lu enhanced the networkbased approach, which was a novel method to increase discrimination in data envelopment analysis [17]. $\mathrm{Li}$ et al. modeled a two-stage structure by assuming the inputs to the second stage, including both the outputs from the first stage and additional inputs to the second stage [18]. Recently, Liu et al. tried to systematically examine two-stage DEA models with undesirable input-intermediate-outputs [19]. Besides, Matin and Azizi introduced a unified general model for efficiency evaluation of network production systems when arbitrary relations between individual subprocesses were allowed [20].

In addition, some studies proposed decomposition approach for measuring the efficiency of network struc- 
ture; as an instance, Chen et al. developed additive efficiency decomposition approach for measuring the efficiency of two-stage network process [21], same as the study by Cook et al., which represented the overall efficiency of an open multistage process as an additive weighted average of the efficiencies of the individual components [22]. In this regard, Kao and Liu developed a multi-period efficiency measurement in DEA to calculate overall and period efficiencies of a DMU at the same time. In their methodology, the overall efficiency was a weighted average of the period efficiencies [23].

Some other new studies focused on network DEA problems from multi-objective point of view, such as the research done by Kao et al. which proposed the Multi-Objective Programming (MOP) method for solving Network DEA (NDEA) models. In the proposed method, the divisional efficiencies (within an organization) and the overall efficiency of the organization were formulated as separate objective functions in the multiobjective programming model [24]. Despotis et al. also used multi-objective programming approach for solving a network DEA problem [25]. This paper wishes to provide some information about the researches done in the area of carpet industry efficiency assessment; to the best of the authors' knowledge, no relevant studies have been done in this area yet. Based on the literature provided above, this research also considers network DEA problem as a multi-objective problem, hence assuming the efficiency of each stage as an objective that should be optimized simultaneously.

\section{Methodology}

In this investigation, DMUs are not treated as a blackbox; instead, the proposed modeling considers internal structure of Iranian Handmade Carpet Company. Thus, the overall performance and the effectiveness of IHCC's sub-processes are measured.

\subsection{Model construction}

Our model disentangles the major Iranian Handmade Carpet Company's activities and places them into the network DEA model. Through the modeling, we consider the handmade carpet industry as a box that can be broken into two main stages, the first one is production stage and the second is marketing stage; marketing stage is divided into two parallel sub-processes named, internal and external markets, which use the desired outputs of the first stage as their own inputs and proportionally cleave inputs between themselves.

The production department uses raw material, weavers' wages, and some other expenses such as designing costs and transportation expenses as its inputs, which are shown by $x_{i j}(i=1, \cdots, m)$, and produce carpets (measured by area) as its output. Since human error is an unavoidable factor in the handmade carpet industry, there are some carpets which are not acceptable for carpet company. Thus, some carpets are perfect, called desired outputs, which enter the second stage as inputs (denoted by $z_{t j}(t=1, \cdots, n)$ ) and some others are imperfect, called undesired outputs $\left(U_{r j}(r=1, \cdots, l)\right)$, which are sent out of the system as wastage. A part of these desired outputs enter the external sales department (denoted by $\alpha_{t j} z_{t j}(t=$ $1, \cdots, n))$ as inputs and the rest enter the internal sales department (denoted by $\left.\beta_{t j} z_{t j}(t=1, \cdots n)\right)$. The profit earned from each market is the output of these sub-processes $\left(y_{1 j}\right.$ for external market sub-process and $y_{2 j}$ for internal market sub-process). Additionally, external sales department has its own inputs, which are independent from the first stage that relates to expenses for customs clearance and transportation, so it is considered as an independent input to the external sales sub-process (denoted by $H_{d j}(d=1, \cdots, p)$ ). Since the internal sales expenses are much less than customs and transportation costs, they can be ignored in the modeling.

Figure 1 illustrates the divisions and components of handmade carpet industry. This study aims to evaluate the efficiency of the overall organization and effectiveness of major departments' operations.

Consider that there are $k$ DMUs, where each $\mathrm{DMU}_{j}(j=1, \cdots, k)$ consists of two main stages, named as production stage and sales stage, as shown in Figure 1. Suppose that each $\mathrm{DMU}_{j}(j=1, \cdots, k)$ has $m$ inputs denoted by $x_{i j}(i=1, \cdots, m)$ to the whole process as well as $n$ desired outputs denoted by $z_{t j}(t=1, \cdots, n)$ from the first stage, which then become inputs to the second stage and are referred to as intermediate measures. Additionally, suppose that each $\mathrm{DMU}_{j}(j=1, \cdots, k)$ has $l$ undesired outputs denoted by $U_{r j}(r=1, \cdots, l)$ from the first stage, which are put out of the system as losses. The desired outputs from the first stage $\left(z_{t j}\right)$ are shared as inputs between two sub-processes of the second stage; the proportion of these inputs measured by $\alpha_{t j}$ is dedicated to the first sub-process while the remaining measured by $\beta_{t j}$ is dedicated to the second one, so $\alpha_{t j}+\beta_{t j}=1$. Furthermore, we assume that the first sub process of second stage has extra inputs from outside of the system, denoted by $H_{d j}(d=1, \cdots, p)$. Eventually, $y_{s j}$ is the outputs of the $s$ th sub-process of the second stage. These parameters are also illustrated in Figure 1.

Consistent with the two-stage frameworks commonly used in the existing literature, the overall organization efficiency can be calculated as the product of the efficiency of two stages as follows [26]:

$$
E_{K}=E_{K 1} \cdot E_{K 2}
$$

where $E_{K 1}$ and $E_{K 2}$ are the efficiencies of production 


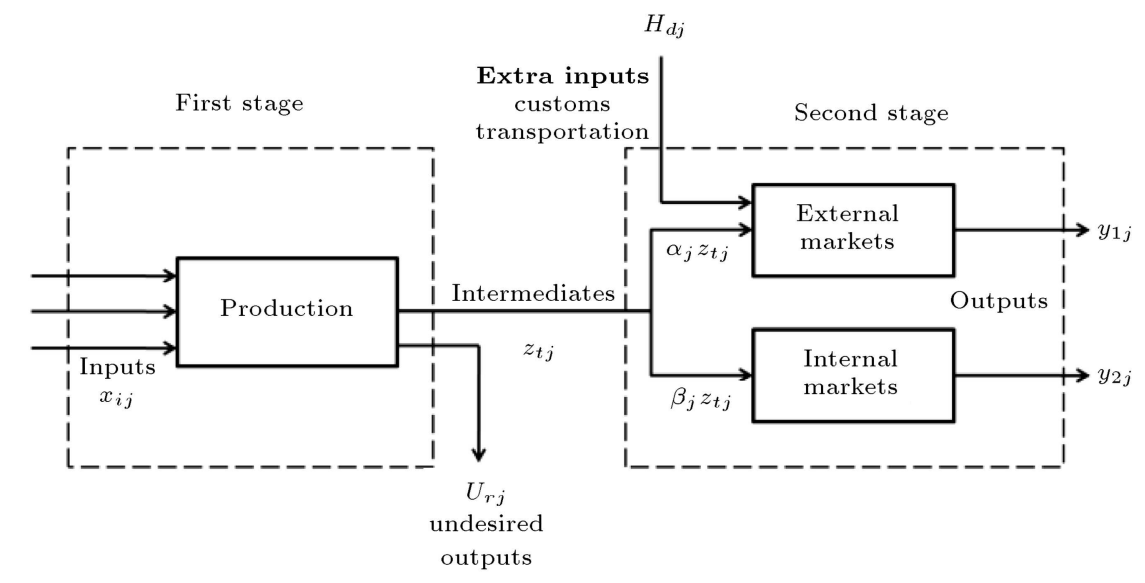

Figure 1. Multi-stage structure of Iranian Handmade Carpet Company (IHCC).

stage and sales stage, respectively. Based upon the Constant Return to Scale (CRS) model [1], the CRS efficiency score for $\mathrm{DMU}_{j}$ in the first and second stages can be calculated, respectively, by the following two equations:

$$
\begin{aligned}
& E_{K 1}=\frac{\sum_{t} w_{t j} z_{t j}-\sum_{r} u_{r j} U_{r j}}{\sum_{i} v_{i j} x_{i j}}, \\
& E_{K 2}=\frac{\sum_{s} u_{s j} y_{s j}}{\sum_{t} w_{t j} z_{t j}+\sum_{d} h_{d j} H_{d j}} .
\end{aligned}
$$

As can be clearly seen, efficiency of each stage is defined as the ratio of the weighted sum of outputs to the weighted sum of inputs. The rationale for the negative sign of the second term in the numerator of efficiency of the first stage is that the outputs $U_{r j}$ are undesirable and to be minimized; thus, they should be decreased in the production process. Besides, it should be considered that $\sum_{s} u_{s j} y_{s j}=\sum u_{1 j} y_{1 j}+\sum u_{2 j} y_{2 j}$.

Thus, the model can be illustrated as follows:

$$
\max \left(\frac{\sum_{t} w_{t j} z_{t j}-\sum_{r} e_{r j} U_{r j}}{\sum_{i} v_{i j} x_{i j}} \cdot \frac{\sum_{s} u_{s j} y_{s j}}{\sum_{t} w_{t j} z_{t j}+\sum_{d} h_{d j} H_{d j}}\right)_{(4)}
$$

subject to:

$$
\begin{aligned}
& \frac{\sum_{s} u_{s j} y_{s j}-\sum_{r} e_{r j} U_{r j}}{\sum_{i} v_{i j} x_{i j}+\sum_{d} h_{d j} H_{d j}} \leq 1, \\
& \frac{\sum_{t} w_{t j} z_{t j}-\sum_{r} e_{r j} U_{r j}}{\sum_{i} v_{i j} x_{i j}} \leq 1, \\
& \frac{\sum_{s} u_{s j} y_{s j}}{\sum_{t} w_{t j} z_{t j}+\sum_{d} h_{d j} H_{d j}} \leq 1, \\
& \frac{\sum u_{1 j} y_{1 j}}{\sum_{t} \alpha_{t j} w_{t j} z_{t j}+\sum_{d} h_{d j} H_{d j}} \leq 1,
\end{aligned}
$$

$$
\frac{\sum u_{2 j} y_{2 j}}{\sum_{t} \beta_{t j} w_{t j} z_{t j}} \leq 1
$$

For a specific $\mathrm{DMU}_{j}$, Constraint (5) considers the system as a whole and represents that the weighted summation of outputs of the whole process is smaller than or equal to that of its inputs. As it was mentioned before, since $U_{r j}$ is undesired outputs, it should be decreased and that is why it has the negative sign in this constrain. Similarly, Constrain (6) is same as Constraint (5), with the difference that it considers the first stage as a box.

Constrain (7) represents efficiency of the whole second stage, which is smaller than or equal to one. Constraints (8) and (9) represent the relative efficiencies of each sub-processes of the second stage to be smaller than or equal to one. As can be clearly seen, Constraints (5) and (7) are redundant, since Constraint (7) can be obtained by Constraints (8) and (9); in addition, Constraint 5 can be obtained by Constraints (6), (8), and (9). Based on relational model [9], we assume that the same factor has the same multiplier, no matter how it is used.

The purpose of this issue is to determine optimal values of the variables $w_{t j}, e_{r j}, u_{s j}, v_{i j}$, and $h_{d j}$ for each $\operatorname{DMU}_{j}(j=1, \cdots, k)$ such that the overall efficiency of the whole system is maximized. It is blindingly evident that this modeling results in a nonlinear objective function, which cannot be solved with linear programming approaches and needs some changes to become solvable. In the following, multiobjective methodology is used to solve this problem.

\subsection{Multi-objective methodology for NDEA}

In the multi-objective approach, the efficiency of each sub-process in addition to efficiency of the whole process is considered as a different objective that should be optimized. Therefore, if the efficiency of each subprocess is assumed as the ratio of weighted outputs to the weighted inputs, the objective functions will be as follow: 


$$
\begin{aligned}
& E_{P j}=\frac{\sum_{t} w_{t j} z_{t j}-\sum_{r} e_{r j} U_{r j}}{\sum_{i} v_{i j} x_{i j}}, \\
& E_{E j}=\frac{\sum u_{1 j} y_{1 j}}{\sum \alpha_{t j} w_{t j} z_{t j}+\sum h_{j} H_{j}}, \\
& E_{I j}=\frac{\sum u_{2 j} y_{2 j}}{\sum \beta_{t j} w_{t j} z_{t j}}, \\
& E_{j}=\frac{\sum u_{1 j} y_{1 j}+\sum u_{2 j} y_{2 j}-\sum_{r} e_{r j} U_{r j}}{\sum_{i} v_{i j} x_{i j}+\sum h_{j} H_{j}},
\end{aligned}
$$

where each of $E_{P j}, E_{E j}, E_{I j}$, and $E_{j}$ is an objective that should be optimized. $E_{P j}, E_{E j}, E_{I j}$, and $E_{j}$ are the efficiencies of production sub-process, external sales sub-process, internal sales sub-process, and total efficiency, respectively. It should be considered that an appropriate model is the one that optimizes all these objectives simultaneously.

As mentioned, the main objective of efficiency evaluation by means of multi-objective network DEA is to maximize all of the above efficiency equations simultaneously. On the other hand, since each efficiency equation in Constraint (10) is a fractional objective, a methodology is used to transform this fractional objective into a linear one. As mentioned before, maximizing each equation is the main objective of the model. Maximizing a fractional equation means to maximize its numerator and, at the same time, to minimize its denominator. Therefore, objective functions of Eq. (10) can be rewritten as follows:

$$
\begin{gathered}
\max \left\{\begin{array}{l}
\sum_{t} w_{t j} z_{t j}-\sum_{r} e_{r j} U_{r j} \\
\sum u_{1 j} y_{1 j} \\
\sum u_{2 j} y_{2 j} \\
\sum u_{1 j} y_{1 j}+\sum u_{2 j} y_{2 j}-\sum_{r} e_{r j} U_{r j}
\end{array}\right. \\
\min \left\{\begin{array}{l}
\sum_{i} v_{i j} x_{i j} \\
\sum \alpha_{t j} w_{t j} z_{j}+\sum h_{d j} H_{d j} \\
\sum \beta_{t j} w_{t j} z_{t j} \\
\sum_{i} v_{i j} x_{i j}+\sum h_{d j} H_{d j}
\end{array}\right.
\end{gathered}
$$

As much as $\sum_{t} w_{t j} z_{t j}$, which is the output of the first stage and simultaneously the input to the second stage, plays two roles, it needs reconsideration. While $\sum_{t} w_{t j} z_{t j}$ is the output of the first stage, it should be maximized and, conversely, while it is the input to the second stage, it should be minimized. Therefore, because of these dual characteristic of this component in the model, it should be equal to a fixed value in order to solve the problem. As a result, Constraint (13) Should be added to the constraints of the model:

$$
\sum_{t} w_{t j} z_{t j}=1
$$

Until now, the fractional multi-objective problem has been transformed into a linear multi-objective problem. In order to solve this multi-objective problem, a method for transforming the multi objective problem into one objective problem is needed, which has the ability to optimize all objectives simultaneously.

Zimmermann [27] applied Bellman and Zadeh's max-min operator [28] to solve the multi-objective linear programming model. This operator enjoyed computation simplicity and some other advantages; however, it was not a compensatory operator. Hence, it did not assure a Pareto-optimal solution [30]. Applying Bellman and Zadeh's max-min operator [28], the optimal solution can be obtained by:

$\max \alpha$,

$$
\begin{aligned}
\alpha & \leq \sum_{t} w_{t j} z_{t j}-\sum_{r} e_{r j} U_{r j}, \\
\alpha & \leq \sum u_{1 j} y_{1 j}, \\
\alpha & \leq \sum u_{2 j} y_{2 j}, \\
\alpha & \leq \sum u_{1 j} y_{1 j}+\sum u_{2 j} y_{2 j}-\sum_{r} e_{r j} U_{r j},
\end{aligned}
$$

$\min \beta$,

$$
\begin{aligned}
\beta & \geq \sum_{i} v_{i j} x_{i j}, \\
\beta & \geq \sum \alpha_{j} w_{1 j} z_{j}+\sum h_{j} H_{j}, \\
\beta & \geq \sum \beta_{j} w_{2 j} z_{j}, \\
\beta & \geq \sum_{i} v_{i j} x_{i j}+\sum h_{j} H_{j} .
\end{aligned}
$$

Subject to:

$$
\begin{aligned}
& \sum_{s} u_{s j} y_{s j}-\sum_{r} e_{r j} U_{r j}-\sum_{i} v_{i j} x_{i j}-\sum_{d} h_{d j} H_{d j} \leq 0 \\
& \sum_{t} w_{t j} z_{t j}-\sum_{r} e_{r j} U_{r j}-\sum_{i} v_{i j} x_{i j} \leq 0 \\
& \sum_{s} u_{s j} y_{s j}-\sum_{t} w_{t j} z_{t j}-\sum_{d} h_{d j} H_{d j} \leq 0 \\
& {\left[\begin{array}{cc}
u_{1 j} & 0 \\
0 & u_{2 j}
\end{array}\right] \cdot\left[\begin{array}{c}
y_{1 j} \\
y_{2 j}
\end{array}\right]-\left[\begin{array}{c}
\alpha_{t j} \\
\beta_{t j}
\end{array}\right] w_{t j} z_{t j}-\left[\begin{array}{cc}
h_{j} & 0 \\
0 & 0
\end{array}\right] \cdot\left[\begin{array}{c}
H_{j} \\
L_{j}
\end{array}\right] \leq 0} \\
& \sum_{t} w_{t j} z_{t j}=1
\end{aligned}
$$


In the constraint set above, the summation of weighted outputs is smaller than the summation of weighted inputs. It can be clearly seen that the proposed methodology converts the nonlinear Constraint set (5) to (9) into the linear programming format by means of Charnes and Cooper transformation [31]. As mentioned before, Constraint (16) can be obtained by summation of Constraints (17) and (18), so it is redundant. Besides, Constraint (18) can be obtained by summation of two constraints summarized in Constraint (19), so this one is redundant, too.

Li utilized Bellman and Zadeh's max-min operator and proposed a two-phase approach [29] using max-min operator as phase I; The optimal solution $\alpha^{*}$ obtained by phase I was supplemented with the constraints of the problem as the minimum solution value in phase II. The two-phase approach was a combination of max-min operator and averaging operator. Since averaging operator had full-compensation property, the solution made by two-phase approach was an efficient one [30]. Therefore, using this two-phase approach is more beneficial than only using max-min operator of Bellman and Zadeh:

$$
\begin{aligned}
& \max \frac{\alpha_{1}+\alpha_{2}+\alpha_{3}+\alpha_{4}}{4} \\
& \alpha^{*} \leq \alpha_{1} \leq \sum_{t} w_{t j} z_{t j}-\sum_{r} e_{r j} U_{r j}, \\
& \alpha^{*} \leq \alpha_{2} \leq \sum u_{1 j} y_{1 j}, \\
& \alpha^{*} \leq \alpha_{3} \leq \sum u_{2 j} y_{2 j}, \\
& \alpha^{*} \leq \alpha_{4} \leq \sum u_{1 j} y_{1 j}+\sum u_{2 j} y_{2 j}-\sum_{r} e_{r j} U_{r j}, \\
& 0 \leq \alpha_{u} \leq 1 \quad u=1,2,3,4 .
\end{aligned}
$$

In this approach, the optimal value $\alpha^{*}$ resulting from the max-min operator in Model (14) is considered as the lower bound of all $\alpha_{u}$. Therefore, it assures the value of each efficiency score is at least equal to $\alpha^{*}$ :

$$
\begin{aligned}
& \min \frac{\beta_{1}+\beta_{2}+\beta_{3}+\beta_{4}}{4}, \\
& \beta^{*} \geq \beta_{1} \geq \sum_{i} v_{i j} x_{i j} \\
& \beta^{*} \geq \beta_{2} \geq \sum \alpha_{j} w_{1 j} z_{j}+\sum h_{j} H_{j}, \\
& \beta^{*} \geq \beta_{3} \geq \sum \beta_{j} w_{2 j} z_{j}, \\
& \beta^{*} \geq \beta_{4} \geq \sum_{i} v_{i j} x_{i j}+\sum h_{j} H_{j}, \\
& 0 \leq \beta_{u} \leq 1, \quad u=1,2,3,4 .
\end{aligned}
$$

In the same manner, the optimal value, $\beta^{*}$, resulting from the max-min operator in Model (15) is considered as the upper bound of all $\beta_{u}$.

Finally, overall efficiency of the system and the relative efficiencies of sub-processes can be calculated from Eq. (10) where $E_{P j}, E_{E j}, E_{I j}$, and $E_{j}$ are the efficiency ratios of production, internal sales department, external sales department, and total efficiency, respectively.

\section{Empirical study}

This paper presents an illustrative example with real data of Iranian Handmade Carpet Company (IHCC). Iranian Handmade Carpet Company has more than 80 years of experience in the fields of weaving, producing, and trading hand-woven carpets. Iran Carpet Company is the major center of hand-woven carpets in IRAN with the following specifications: 10000 weavers, 500 branches in villages and rural areas, and 100 branches in major cities. Data of IHCC are gathered in a period of two years from the beginning of 2012 to the end 2013 and the average is summarized in Table 1. For establishing the main departments in addition to main parameters of input, intermediate, and output, broad consultations are done with IHCC's specialists, including production managers, marketing managers, and sales managers. Upon the consultations done with carpet specialists, we assume 15 DMUs as the main carpet industry's DMUs, which are based on the different categories of carpets such as Tabriz carpet, Yazd carpet, Isfahan carpet, etc. For each DMU, we assume three inputs, named raw material expenses $\left(X_{1 j}\right)$; weavers' wages $\left(X_{2 j}\right)$; and other expenses related to plan, design, and the equipment needed for weaving a carpet $\left(X_{3 j}\right)$, which are measured by current currency of Iran. The amount of perfect carpets woven by weavers is measured by area $\left(\mathrm{m}^{2}\right)$, which is assumed as desired output of the first stage $\left(Z_{t j}\right)$ that enters the second stage. Besides, undesired or imperfect carpets are denoted by $U_{j}$, which are sent outside the system. The proportion of the desired outputs, denoted by $\alpha_{t j} z_{t j}$, enters the external markets and the remaining, denoted by $\beta_{t j} z_{t j}$, enters the internal markets. Consider that $\alpha_{t j}$ and $\beta_{t j}$ are the parameters of the model and $\alpha_{t j}+\beta_{t j}=1$. In addition, independent inputs to the external markets are denoted by $H_{j}$. The profit earned from each market is the outputs of the sub-processes, denoted by $y_{1 j}$ and $y_{2 j}$ for external and internal sales sub-processes, respectively. The data set for a one-year period is summarized in Table 1. The results calculated by both models are reported in Table 2, where the first four columns represent the results of the first methodology and the remaining show the results of the second methodology. The first and 5 th columns of Table 2 show the overall efficiency 
Table 1. Data set of Iranian Handmade Carpet Company (IHCC's archives, 2012-2013).

\begin{tabular}{|c|c|c|c|c|c|c|c|c|c|}
\hline \multirow[b]{2}{*}{$\mathrm{DMU}^{-}$} & \multicolumn{3}{|c|}{ First stage's inputs } & \multicolumn{2}{|c|}{ Intermediate variables } & \multicolumn{2}{|c|}{ Second stage's inputs } & \multicolumn{2}{|c|}{ Second stage's outputs } \\
\hline & $\begin{array}{c}\text { Raw } \\
\text { material }\end{array}$ & Wages & $\begin{array}{c}\text { Other } \\
\text { expenses }\end{array}$ & $\begin{array}{l}\text { Desired } \\
\text { output }\end{array}$ & $\begin{array}{l}\text { Undesired } \\
\text { output }\end{array}$ & $\beta$ & $\begin{array}{l}\text { Customs and } \\
\text { transportation }\end{array}$ & $\begin{array}{l}\text { External } \\
\text { markets' } \\
\text { earning }\end{array}$ & $\begin{array}{c}\text { Internal } \\
\text { markets' } \\
\text { profit }\end{array}$ \\
\hline Dep1 & 56 & 190 & 4.1 & 470 & 24 & 0.300 .70 & 22 & 103 & 28 \\
\hline Dep2 & 282 & 298 & 6.8 & 1280 & 75 & 0.470 .53 & 58 & 579 & 80 \\
\hline Dep3 & 38 & 122 & 5.8 & 800 & 61 & 0.230 .77 & 26 & 285 & 317 \\
\hline Dep4 & 82 & 262 & 23 & 310 & 19 & 0.160 .84 & 8 & 86 & 36 \\
\hline Dep 5 & 18 & 208 & 15 & 610 & 21 & 0.180 .82 & 5 & 172 & 87 \\
\hline Dep6 & 129 & 295 & 30 & 1120 & 71 & 0.340 .66 & 53 & 314 & 58 \\
\hline Dep7 & 79 & 132 & 29 & 600 & 13 & $0.25 \quad 0.75$ & 22 & 169 & 66 \\
\hline Dep8 & 54 & 128 & 21 & 460 & 12 & $0.26 \quad 0.74$ & 18 & 128 & 59 \\
\hline Dep9 & 63 & 98 & 15 & 710 & 30 & 0.310 .69 & 32 & 198 & 36 \\
\hline Dep10 & 43 & 85 & 13 & 360 & 12 & 0.140 .86 & 8 & 99 & 26 \\
\hline Dep11 & 76 & 129 & 17 & 530 & 19 & 0.190 .81 & 16 & 148 & 26 \\
\hline Dep12 & 68 & 120 & 25 & 860 & 34 & 0.170 .83 & 19 & 241 & 90 \\
\hline Dep13 & 85 & 124 & 2.7 & 370 & 28 & 0.150 .85 & 12 & 103 & 161 \\
\hline Dep14 & 95 & 75 & 7.9 & 250 & 12 & $0.23 \quad 0.77$ & 7 & 69 & 20 \\
\hline Dep15 & 54 & 55 & 9.3 & 320 & 30 & 0.130 .87 & 5 & 88 & 13 \\
\hline
\end{tabular}

Table 2. Results of efficiency measurement.

\begin{tabular}{lcccc}
\hline \multirow{2}{*}{ DMU } & \multicolumn{4}{c}{ First approach } \\
\cline { 2 - 5 } & $\begin{array}{c}\text { Total } \\
\text { efficiency }\end{array}$ & $\begin{array}{c}\text { Production } \\
\text { efficiency }\end{array}$ & $\begin{array}{c}\text { External sales } \\
\text { efficiency }\end{array}$ & $\begin{array}{c}\text { Internal sales } \\
\text { efficiency }\end{array}$ \\
\hline Dep1 (Isfahan) & 0.51 & 0.64 & 0.56 & 0.55 \\
Dep2 (Tabriz) & 0.84 & 0.68 & 1.00 & 0.79 \\
Dep3 (Zabol) & 0.78 & 1.00 & 0.53 & 1.00 \\
Dep4 (Ghom) & 0.59 & 0.45 & 0.71 & 0.59 \\
Dep5 (Naeen) & 0.81 & 1.00 & 0.87 & 0.71 \\
Dep6 (Kerman) & 0.44 & 0.33 & 0.52 & 0.22 \\
Dep7 (Ilam) & 0.56 & 0.58 & 0.62 & 0.58 \\
Dep8 (Birjand) & 0.64 & 0.75 & 0.65 & 0.61 \\
Dep9 (Kashan) & 0.47 & 0.76 & 0.54 & 0.54 \\
Dep10 (Yasouj) & 0.60 & 1.00 & 0.72 & 0.62 \\
Dep11 (Yazd) & 0.48 & 0.61 & 0.57 & 0.54 \\
Dep12 (Hamedan) & 0.56 & 0.66 & 0.63 & 0.68 \\
Dep13 (Shahrkord) & 1.00 & 1.00 & 1.00 & 0.99 \\
Dep14 (Kashmar) & 0.63 & 0.91 & 0.73 & 0.21 \\
Dep15 (Bijar) & 0.53 & 1.00 & 0.68 & 0.19 \\
\hline
\end{tabular}

scores obtained by the first and second approaches, respectively. In addition, partial efficiency scores of all departments are summarized in Table 2.

\section{Discussion}

The results summarized in Table 2 can be used to develop beneficial management strategies for future years. For instance, Shahrkord, Tabriz, Naeen, and Zabol carpets have higher total efficiency scores among all 15 departments. Thus, during the production planning and resource allocation in the following year, more resources will be allocated to these special categories of handmade carpet in order to maximize the profit and productivity of the company.

One of the high-priority policies of Iranian Handmade Carpet Company is conducting the production procedures with regards to export's needs; consequently, it is so important for IHCC's decision makers to know what category of carpets has the most efficiency in external markets. In other words, by distinguishing those kinds of carpet that can bring more profit for the company through export, IHCC can increase its income properly, especially now that the value of Dollar has increased greatly in relation to Rial. Based on the information summarized in Table 2, the 
most efficient categories of Iranian handmade carpet for export include the Tabriz, Naeen, and Shahrekord carpets. In other words, these categories of carpets are the best categories for export and have the highest external sales efficiency scores.

In addition to export, internal sale is so important for IHCC. Since, if IHCC's managers get access to scientific information about the efficiency of different carpet categories in internal markets, they can make logical decisions on the production plan for the amounts of different categories in future years. In addition, about $40 \%$ of IHCC's income is earned through internal markets in average; therefore, efficiency assessment of different categories in domestic markets is so important. By means of the methodology provided in this study and the efficiency assessment in Table 2, it can be concluded that Zabol, Shahrkord, and Tabriz are the most efficient categories in internal markets.

In addition, by focusing on partial effectiveness of different departments, most efficient carpets among production departments can be classified as Zabol, Naeen, Yasuj, Shahrkord, and Bijar. It means that the production departments of these DMUs produce the maximum amounts of desired output in proportion to their inputs relative to other DMUs.

In comparison, the model proposed by this paper works better than the previous ones because of two main reasons. The first reason is related to the results obtained from experimental data. As Table 2 indicates, results show that a DMU will be efficient if and only if all of its departments are efficient. As an illustration, consider the third DMU, which is efficient in production and internal sales; however, the external sales department of this DMU does not work properly and it has an efficiency score of 0.53. Thus, the consequence is that total efficiency score of this DMU must be less than one, because all departments of this DMU are not efficient; this is true, because the proposed model measured the amount of 0.78 for total efficiency score. In fact, a DMU is efficient only if all of its' departments are efficient and this reasonable result can be obtained from the proposed MOP-NDEA approach. Besides, for the 13th DMU, which is efficient in production, internal sales, and external sales departments, total efficiency score is measured as 1 , showing that this DMU is completely efficient.

The second reason is related to the manner of solving the problem. By means of MOP in NDEA, the partial and total efficiencies can be optimized in a cohesive manner.

\section{Conclusion}

The main objective of this paper was to assess the performance of handmade carpet industry for the first time. To achieve this goal, this study measured the efficiency and effectiveness of Iranian Handmade Carpet Company (IHCC), which is a multi-stage system with extra inputs, undesired outputs, and shared variables. Because of network structure of the system, overall efficiency equation resulted in a nonlinear function. In order to convert this nonlinear function to a linear one, a new approach for assessing the overall efficiency and partial effectiveness of each sub-processes was introduced.

In this research, multi-objective programming was used in order to solve a network DEA problem. By means of MOP in NDEA, the partial and total efficiencies could be optimized in a cohesive manner. This approach considered the network DEA problem as a multi- objective one and aimed to maximize total and partial efficiencies of the network structure, simultaneously, by solving just one model. Results calculated from empirical data of IHCC distinguished the most efficient departments and prepared some brilliant information for decision makers to make strategic decisions in future. Further researches can explore other multi-objective network DEA models for measuring the performance of more complex multi-stage networks with undesired outputs in variable returnto-scale mode. In addition, due to the importance of carpet industry, more investigations in this area are needed.

\section{References}

1. Charnes, A., Cooper, W.W. and Rhodes, E. "Measuring the efficiency of decision making units", European Journal of Operational Research, 2, pp. 429-444 (1978).

2. Cook, W.D. and Seiford, L.M. "Data envelopment analysis (DEA)-thirty years on", European Journal of Operational Research, 192, pp. 1-17 (2009).

3. Emrouznejad, A., Parker, B.R. and Tavares, G. "Evaluation of research in efficiency and productivity: A survey and analysis of the first 30 years of scholarly literature in DEA", Socio-Economic Planning Sciences, 42, pp. 151-157 (2008).

4. Liu, J.S., Lu, L.Y., Lu, W.-M. and Lin, B.J. "A survey of DEA applications", Omega, 41, pp. 893-902 (2013).

5. Liu, J.S., Lu, L.Y., Lu, W.-M. and Lin, B.J. "Data envelopment analysis 1978-2010: A citation-based literature survey", Omega, 41, pp. 3-15 (2013).

6. Zhou, P., Ang, B.W. and Poh, K.-L. "A survey of data envelopment analysis in energy and environmental studies", European Journal of Operational Research, 189, pp. 1-18 (2008).

7. Liu, J.S., Lu, L.Y.Y., Lu, W.-M. and Lin, B.J.Y. "Data envelopment analysis 1978-2010: A citationbased literature survey", Omega, 41, pp. 3-15 (2013).

8. Färe, R. and Grosskopf, S. "Network DEA", SocioEconomic Planning Sciences, 34, pp. 35-49 (2000). 
9. Kao, C. and Hwang, S.-N. "Efficiency decomposition in two-stage data envelopment analysis: An application to non-life insurance companies in Taiwan", European Journal of Operational Research, 185, pp. 418-429 (2008).

10. Kao, C. and Hwang, S.-N. "Efficiency measurement for network systems: IT impact on firm performance", Decision Support Systems, 48, pp. 437-446 (2010).

11. Kao, C. "Network data envelopment analysis: A review", European Journal of Operational Research, 239, pp. 1-16 (2014).

12. Cook, W.D., Liang, L. and Zhu, J. "Measuring performance of two-stage network structures by DEA: A review and future perspective", Omega, 38, pp. 423430 (2010a).

13. Tone, K. and Tsutsui, M. "Network DEA: a slacksbased measure approach", European Journal of Operational Research, 197, pp. 243-252 (2009).

14. Kao, C. "A linear formulation of the two-level DEA model", Omega, 36, pp. 958-962 (2008).

15. Kao, C. "Efficiency decomposition in network data envelopment analysis: A relational model", European Journal of Operational Research, 192, pp. 949-962 (2009).

16. Hsieh, L.-F. and Lin, L.-H. "A performance evaluation model for international tourist hotels in Taiwan-An application of the relational network DEA", International Journal of Hospitality Management, 29, pp. 1424 (2010).

17. Liu, J.S. and Lu, W.-M. "DEA and ranking with the network-based approach: a case of R\&D performance", Omega, 38, pp. 453-464 (2010).

18. Li, Y., Chen, Y., Liang, L. and Xie, J. "DEA models for extended two-stage network structures", Omega, 40, pp. 611-618 (2012).

19. Liu, W., Zhou, Z., Ma, C., Liu, D. and Shen, W. "Two-stage DEA models with undesirable inputintermediate-outputs", Omega, 56, pp. 74-87 (2015).

20. Matin, R.K. and Azizi, R. "A unified network-DEA model for performance measurement of production systems", Measurement, 60, pp. 186-193 (2015).

21. Chen, Y., Du, J., David Sherman, H. and Zhu, J. "DEA model with shared resources and efficiency decomposition", European Journal of Operational Research, 207, pp. 339-349 (2010).

22. Cook, W.D., Zhu, J., Bi, G. and Yang, F. "Network DEA: Additive efficiency decomposition", European Journal of Operational Research, 207, pp. 1122-1129 (2010b).

23. Kao, C. and Llu, S.-T. "Multi-period efficiency measurement in data envelopment analysis: The case of Taiwanese commercial banks", Omega, 47, pp. 90-98 (2014).

24. Kao, H.-Y., Chan, C.-Y. and Wu, D.-J. "A multiobjective programming method for solving network DEA", Applied Soft Computing, 24, pp. 406-413 (2014).
25. Despotis, D.K., Koronakos, G. and Sotiros, D. "A multi-objective programming approach to network DEA with an application to the assessment of the academic research activity", Procedia Computer Science, 55, pp. 370-379 (2015).

26. Liang, L., Cook, W.D. and Zhu, J. "DEA models for two-stage processes: Game approach and efficiency decomposition", Naval Research Logistics (NRL), 55, pp. 643-653 (2008).

27. Zimmermann, H.-J. "Fuzzy programming and linear programming with several objective functions", Fuzzy Sets and Systems, 1, pp. 45-55 (1978).

28. Bellman, R.E. and Zadeh, L.A. "Decision-making in a fuzzy environment", Management Science, 17, pp. B-141-B-164 (1970).

29. Li, R.J. "Multiple objective decision making in a fuzzy environment", Ph.D. Thesis, Department of Industrial Engineering, Kansas State University, Manhattan, US (1990).

30. Shahnazari-Shahrezaei, P., Tavakkoli-Moghaddam, R. and Kazemipoor, H. "Solving a multi-objective multiskilled manpower scheduling model by a fuzzy goal programming approach", Applied Mathematical Modelling, 37, pp. 5424-5443 (2013).

31. Charnes, A. and Cooper, W.W. "Programming with linear fractional functionals", Naval Research Logistics Quarterly, 9, pp. 181-186 (1962).

\section{Biographies}

Seyed Hessameddin Zegordi is Professor of Industrial Engineering in the Faculty of Industrial \& Systems Engineering at Tarbiat Modares University, Tehran, Iran. He received his $\mathrm{PhD}$ degree from the Department of Industrial Engineering and Management at Tokyo Institute of Technology, Japan, in 1994. He holds an MSc degree in Industrial Engineering and Systems from Sharif University of Technology, Iran, and a BSc degree in Industrial Engineering from Isfahan University of Technology, Iran. His research interests include mathematical modeling for production planning problems, location \& layout design, metaheuristics, supply chain management, quality management, and productivity \& performance measurement.

Azadeh Omid is a PHD student at Tarbiat Modares University, Department of Management. She received BSc degree in Mechanical Engineering from Iran University of Science and Technology in 2011, and MSc degree in Industrial Engineering from Tarbiat Modares University, Tehran, Iran, in 2013. Her research interests include applications of operations research, productivity and performance management, supply chain management, multi-objective optimization, and robust optimization. 